\title{
Agresivno vedenje $v$ procesu dolgotrajne rehabilitacije po pridobljeni možganski poškodbi: pregled izkušenj iz prakse
}

\author{
Maša Šemrov*
}

Center KORAK za osebe s pridobljeno možgansko poškodbo

\begin{abstract}
Povzetek: Agresivno vedenje posameznika s pridobljeno možgansko poškodbo (PMP) pogosto ovira pri uspešnem vračanju v okolje, pri čemer se vzroki za pojavljanje in oblike agresivnega vedenja med posamezniki s PMP razlikujejo. V prispevku predstavljamo tiste posledice PMP, za katere v procesu dolgotrajne rehabilitacije opažamo, da se povezujejo s pojavljanjem agresivnega vedenja in ovirajo njegovo obravnavo. Izpostavljamo predvsem težave z inhibicijo odziva, zmanjšanim uvidom, sprejemanjem lastnega stanja in z njim povezanimi čustvenimi težavami ter osebnostne in vedenjske spremembe. Pri obravnavi agresivnega vedenja v procesu dolgotrajne rehabilitacije uporabljamo individualno prilagojen pristop, ki nudi podporo in posamezniku s PMP omogoča razvijanje bolj učinkovitih načinov spoprijemanja z lastnimi zmanjšanimi zmožnostmi. Napredki so omejeni na konkretne situacije, zato ni verjetno, da se agresivno vedenje ne bi več pojavljalo. Kljub temu pa poznavanje problematike lahko pripomore k zmanjševanju tako pojavnosti agresivnega vedenja kot tudi vpliva na življenje posameznika s PMP.
\end{abstract}

Ključne besede: pridobljena možganska poškodba, agresivnost, rehabilitacija, obravnava agresivnega vedenja

\section{Aggressive behaviour in the process of long-term rehabilitation after acquired brain injury: Review of practice}

\author{
Maša Šemrov*
}

Center KORAK for the Persons with Acquired Brain Injury, Slovenia

\begin{abstract}
Aggressive behaviour that follows acquired brain injury (ABI) is often hampering successful re-integration into the social life wherein causes and types vary. We focus on the consequences of ABI which are associated with the occurrence of aggressive behaviour and also hamper its treatment in the process of long-term rehabilitation. Specifically, we analyse changes in inhibitory control, reduced self-awareness, problems with accepting the situation and consequent emotional issues, and changes in personality and behaviour. In the process of long-term rehabilitation, we use an individually tailored approach, which aims to support and enable a person with ABI to develop more effective ways to cope with disabilities. As the outcomes in terms of progress are limited to specific situations, it is unlikely that aggressive behaviour would not repeat. We nevertheless find that knowledge of this phenomenon may reduce the frequency of aggressive behaviour and its impact on everyday functioning.
\end{abstract}

Keywords: acquired brain injury, aggressive behaviour, rehabilitation, treatment

\footnotetext{
*Naslov/Address: mag. Maša Šemrov, Center KORAK za osebe s pridobljeno možgansko poškodbo, Kidričeva cesta 53, 4000 Kranj, e-mail: masa.mitrovic@gmail.com
}

Članek je licenciran pod pogoji Creative Commons Attribution 4.0 International licence. (CC-BY licenca).

The article is licensed under a Creative Commons Attribution 4.0 International License (CC-BY license). 
Napredek na področju tehnologije in večja dostopnost ustrezne urgentne oskrbe poškodovancev na terenu sta privedla do večjega števila oseb, ki preživijo po težki možganski poškodbi (Grabljevec, 2011), na žalost pa ima približno tretjina trajne posledice na fizičnem, kognitivnem in vedenjskem področju (Arciniegas in McAllister, 2008). Možganske poškodbe ostajajo globalna »tiha epidemija« in $\mathrm{v}$ razvitem svetu predstavljajo velik medicinski in socialnodemografski problem (Grabljevec, 2009).

Posledice možganskih poškodb so zelo raznolike in odvisne od narave, obsega in intenzitete poškodbe, poteka zgodnjega okrevanja, pred poškodbo dosežene ravni sposobnosti in stila življenja, pogojev $\mathrm{v}$ okolju in številnih drugih dejavnikov (Radonjič Miholič, 2005). Lahko se kažejo kot težave, oviranosti ali spremembe na telesnem, kognitivnem, osebnostnem, čustvenem in vedenjskem področju.

Pridobljena možganska poškodba (PMP) je definirana kot poškodba možganov, ki nastane po rojstvu in ni povezana s prirojenimi in razvojnimi motnjami oz. napredujočimi poškodbami možganov ter tako vključuje širok spekter motenj $\mathrm{z}$ različnimi izvori (npr. nezgodna možganska poškodba, tumor, možgansko-žilne bolezni, infekcije ipd.; Rees idr., 2007). Iz omenjene definicije izhaja, da pojem PMP zajema raznoliko skupino posameznikov, ki se med seboj razlikujejo glede na vzrok nastanka in obseg možganske poškodbe, stopnje oškodovanosti ter težav v vsakodnevnem funkcioniranju.

Vzroki za pojavljanje agresivnega vedenja zajemajo vrsto, obseg in lokacijo možganske poškodbe, starost in slabše socialno funkcioniranje pred PMP, prav tako pa se pojav agresivnega vedenja po PMP povezuje z depresijo, lezijami frontalnega režnja ter zlorabo alkohola in drugih substanc (Tateno idr., 2003). Pojav agresivnega vedenja v procesu rehabilitacije predstavlja tveganje tako za osebe s PMP kot tudi zaposlene, zato je razumljivo, da sta verbalna in fizična agresivnost med najbolj raziskanimi področji vedenjskih težav po PMP (Kelly idr., 2008). Negativne posledice, ki lahko nastanejo zaradi socialno neprimernega vedenja posameznikov s PMP, kamor spada tudi agresivno vedenje, zajemajo izključitev iz storitev, ki jih potrebujejo, povečane stroške pri zagotavljanju ustrezno usposobljenega kadra $\mathrm{v}$ ustanovah, kazniva dejanja, neželene sprejeme v neprimerno institucionalno oskrbo in, ne nazadnje, tudi veliko stisko svojcev, zaposlenih in njih samih (Todd idr., 2004).

$\mathrm{V}$ nadaljevanju bomo predstavili spremembe po PMP, za katere pri delu na področju dolgotrajne rehabilitacije opažamo, da lahko vplivajo na razvoj agresivnega vedenja posameznika s PMP. O dolgotrajni celostni rehabilitaciji oseb $\mathrm{S}$ pridobljeno možgansko poškodbo $\mathrm{v}$ Sloveniji govorimo po zaključeni medicinski in psihosocialni rehabilitaciji, ko je posameznik odpuščen $\mathrm{v}$ oskrbo $\mathrm{v}$ domače okolje in ima možnost ter hkrati izpolnjuje določene pogoje za vključitev $\mathrm{v}$ proces dolgotrajne rehabilitacije $\mathrm{z}$ vključevanjem $\mathrm{v}$ storitev socialnega varstva. Storitev se izvaja v obliki dnevnega centra, zaradi česar ostajajo posamezniki s pridobljeno možgansko poškodbo del širšega družbenega sistema, saj niso $\mathrm{v}$ institucionalnem varstvu. Temelji na multidisciplinarnem pristopu, ki je usmerjen $\mathrm{v}$ doseganje ciljev individualnega načrta rehabilitacije, ki jih opredelita posameznik s PMP in strokovni delavec.

\section{Spremembe na kognitivnem področju}

Spremembe na kognitivnem področju zajemajo različne stopnje oškodovanosti sistema pozornosti, spomina, izvršilnih funkcij, vidno-prostorskih ter jezikovno-govornih sposobnosti. Stopnja prizadetosti je odvisna od velikosti in mesta poškodbe ter ima pomemben vpliv na izid rehabilitacije (Čižman Štaba in Sagadin, 2016). Glede na obstoječe študije lahko omenjene spremembe povežemo s poškodbami frontalnih režnjev in subkortikalnih predelov (Vaishnavi idr., 2009), zaradi česar prihaja do spremenjenih odzivov na dražljajske situacije, pri čemer obstaja jasna povezava med zmanjšano zmožnostjo inhibicije na nevrokognitivnih testih in povečano reaktivnostjo $\mathrm{v}$ čustveno intenzivnih situacijah (McDonald idr., 2010). Tako se med vplivi PMP na vedenje posameznika pogosto opaža znižana zmožnost inhibicije vedenja, ki je ključna za doseganje cilja in zadovoljevanje potreb na družbeno sprejemljiv način.

V socialnih interakcijah ima zmožnost inhibicije odziva pomembno vlogo, saj omogoča, da se na situacije odzovemo na socialno primeren način, prav tako pa omogoča tudi sposobnost učinkovitega reševanja težav. Fleksibilno, k cilju usmerjeno vedenje zahteva prilagojen kognitivni kontrolni sistem za izbiranje med kontekstualno pomembnimi informacijami ter za organiziranje in optimiziranje poti procesiranja (Ridderinkhof idr., 2004). Kadar mora določena aktivnost tekmovati $\mathrm{z}$ drugimi močnimi alternativami, se mora kognitivna kontrola upirati interferencam, da bi zagotovila uspešnost pri izvedbi določenega procesa. Po nekaterih ugotovitvah pa se sposobnost slabše inhibicije po PMP na Stroopovem testu ni povezovala toliko s kontrolo interference kot $\mathrm{s}$ počasnim procesiranjem informacij, utrujenostjo in slabšo vzburjenostjo (Dimoska-Di Marco idr., 2011). Kot verjetnejši vzrok za pojavljanje socialno neprimernih oblik vedenja po PMP se zato namesto popolne odpovedi sposobnosti inhibicije omenja odložena oz. upočasnjena aktivacija le-te (Pearce idr., 2016).

Sposobnost spremljanja in primerjanja tekočih aktivnosti in rezultatov izvedbe s posameznikovimi cilji je ključna za uspešno sprejemanje odločitev, pričemer v procesu dolgotrajne rehabilitacije oseb po PMP opažamo, da se posamezniki v socialnih interakcijah velikokrat odzivajo impulzivno. Prav tako posamezniki po PMP, pri katerih se pojavlja agresivno vedenje, uporabljajo manj uspešne strategije reševanja vaj kognitivnega treninga, so pri reševanju impulzivni oz. je pri njih prisotna težja oškodovanost kognitivnih funkcij. Primanjkljaji se med posamezniki s PMP lahko precej razlikujejo, zato opažamo, da je pri oceni funkcioniranja treba upoštevati tudi vpliv težav na njihovo vsakodnevno funkcioniranje ter sposobnost, da kompenzirajo in do določene mere zaobidejo oz. zmanjšajo obstoječe primanjkljaje.

Strokovno delo za zmanjševanje vpliva sprememb na področju inhibicije odziva v procesu dolgotrajne rehabilitacije zajema individualno delo (poznavanje sprožilnih situacij, učenje primernih strategij kompenziranja) in prilagoditev situacije (posamezniku s PMP se nameni več časa za oblikovanje ustreznega odziva, prav tako je pomembno, da se do največje možne mere zmanjša vpliv dejavnikov, ki bi lahko povzročili neželen odziv, npr. hrup, dajanje zaporednih 
in ne sočasnih navodil ipd.). Opažamo tudi, da v primerih pojavljanja verbalne in fizične agresivnosti pomembno vlogo pri prekinitvi agresivnega vedenja opravljajo zaposleni, s tem da posežejo v situacijo. Na takšen način posameznik po PMP dobi prvo povratno informacijo o neprimernosti njegovega vedenja. Menimo, da prekinjanje agresivnega vedenja s strani zaposlenih predstavlja zunanjo pomoč pri aktivaciji inhibicije posameznika s PMP, saj se navadno agresivno vedenje s tem tudi zaključi. V primerih hujših oblik agresivnega vedenja pa postopanje po protokolih omogoča zaposlenim izvedbo posameznih korakov za obravnavo agresivnega vedenja in zmanjševanje njegovega vpliva.

$\mathrm{S}$ pogostim pojavljanjem verbalne in fizične agresivnosti se povezuje tudi znižana zmožnost na govorno-jezikovnem področju (James in Young, 2013), zato je pri obravnavi agresivnih oblik vedenja treba upoštevati tudi govornojezikovne sposobnosti in spretnosti posameznikov s PMP. Prav tako jezikovno procesiranje lahko pomaga pri regulaciji izvršilnih funkcij, ki so nujne za inhibicijo agresivnega vedenja, to so abstraktno mišljenje, kognitivno uravnavanje emocij in refleksija(Milleridr., 2008). Obravnavo agresivnega vedenja $\mathrm{v}$ procesu dolgotrajne rehabilitacije največkrat izvajamo $\mathrm{s}$ podajanjem povratne informacije po dogodku, iskanjem vzrokov in učenjem drugih ustreznih odzivov, kar pa je pri osebah z zmerno in težjo obliko PMP omejeno na konkretne situacije v strukturiranem okolju (Wood in Alderman, 2011). Opažamo, da usmerjen pogovor med posameznikom s PMP in strokovnim delavcem pomaga pri jezikovnem procesiranju in ima razbremenilno funkcijo.

Med bolj pogostimi opažanji je tudi to, da $\mathrm{v}$ primeru, ko je kognitivna oškodovanost eden glavnih razlogov za vztrajanje vedenjskih motenj, visoko strukturirano okolje v rehabilitacijski ustanovi omogoča učinkovito podajanje povratnih informacij skozi oblikovanje intervencij za preoblikovanje vedenja (Wood in Alderman, 2011).

\section{Vpliv uvida na obravnavo agresivnega vedenja}

Posamezniki s PMP pri postavljanju ciljev v rehabilitaciji bolj kot težave na področju kognicije, osebnosti in čustvovanja kot moteče izpostavljajo spremembe in zmanjšane zmožnosti na telesnem področju. Razlog za to, da lažje poročajo o telesnih težavah, leži v tem, da se te bolj opazijo oz. je izpostavljanje telesnih težav bolj socialno sprejemljivo, možno pa je tudi oboje (Hart idr., 2004).

Nevrološke razlage za oškodovanost sposobnosti ustreznega uvida ne dajo enoznačnih rezultatov. Nekonsistentnost rezultatov $\mathrm{s}$ tega področja se pripisuje kompleksnosti konstrukta uvida, razpršeni naravi poškodb po možganski poškodbi in dejstvu, da so psihološki dejavniki redko upoštevani (Belchev idr., 2017). Zmožnost posameznikovega vpogleda $\mathrm{v}$ dejansko zdravstveno stanje se seveda lahko sčasoma izboljša, vendar imamo pogosto opravka tudi s stanji, ko govorimo o dolgotrajni in organsko pogojeni nekritičnosti oz. zmanjšani stopnji vpogleda in osebne sposobnosti samoregulacije (Starovasnik Žagavec, 2012). V nasprotju s težje poškodovanimi, pri katerih gre pogosto za pomanjkljiv uvid $\mathrm{v}$ njihove težave, lahko lažje poškodovani kažejo stopnjevano pozornost in občutljivost za izgubo ali zmanjšanje prejšnjih zmožnosti (Jakopec, 2010).

Zmanjšan uvid ima lahko negativen vpliv na izid rehabilitacije takrat, ko posameznik, ki ne zaznava lastnih zmanjšanih zmožnosti, odklanja obravnavo ali se ji upira (Hart idr., 2004; Starovasnik Žagavec, 2012). Poleg tega zmanjšan uvid ni uniformno prisoten pri vseh vrstah primanjkljajev, ampak so zanj bolj dovzetni primanjkljaji na kognitivnem in vedenjskem področju kot spremembe na fizičnem nivoju. Zaradi tega posamezniki s PMP v procesu dolgotrajne rehabilitacije težje poročajo ali popolnoma spregledajo spremembe in težave na kognitivnem in vedenjskem področju v primerjavi s spremembami na telesnem področju, kjer so te bolj očitne. Težave $\mathrm{z}$ uvidom se povezujejo tudi $\mathrm{z}$ uporabo obrambnih mehanizmov, kot sta zanikanje in projekcija (Belchev idr., 2017). V procesu dolgotrajne rehabilitacije opažamo, da slabša sposobnost uvida vpliva na uspešnost intervencij za doseganje sprememb na vedenjskem področju, saj posamezniki s PMP, pri katerih se pojavlja agresivno vedenje, slabše zaznavajo svoje zmanjšane zmožnosti na kognitivnem področju, lahko pa nekritično ocenjujejo tudi vpliv telesnih zmanjšanih zmožnosti. Delo na vzpostavljanju ustreznega uvida predstavlja izziv pri delu z osebami s PMP, pri čemer so odpori pogosti. Prav tako se ob povečanju uvida frustracija lahko celo še poveča (Anson in Ponsford, 2006; Cooper-Evans idr., 2008), kar lahko dodatno generira agresivno vedenje.

\section{Spremembe na področju osebnosti, čustvovanja in vedenja}

Vedenje oseb po možganski poškodbi je pogosto obremenjeno s težavami, kot so nestabilnost, nizka frustracijska toleranca in pomanjkanje nadzora, kar se kaže v razdražljivosti, neprimernem vedenju, impulzivnosti in/ali pretirani togosti ter zmanjšanih sposobnostih za reševanje težav (Jakopec, 2010). Za impulzivno vedenje je značilno, da posameznik odreagira ne glede na okoliščine in posledice ter se ne ozira na to, kakšne učinke bo njegovo vedenje imelo na druge (Čižman Štaba in Sagadin, 2016). Pojavlja se tudi pretirana usmerjenost vase, ki se kaže kot nesposobnost videnja stvari oz. situacij s perspektive druge osebe (Čižman Štaba in Sagadin, 2016). Čustvene in vedenjske težave predstavljajo zmanjšano sposobnost regulacije oz. zmanjšano izraženost inhibicije in/ali gona (McDonald idr., 2010). Regulacija čustev je ključen element socialne kognicije, saj v širšem smislu označuje sposobnost posameznika, da uporablja inhibicijsko kontrolo nad tem, kako se izraža in/ali usmerja svoja čustva v različnih oblikah socialne interakcije (Cattran idr., 2011).

V procesu dolgotrajne rehabilitacije opažamo, da je sprožilec agresivnega vedenja večinoma frustracija, ki ima različne izvore, in sicer lahko nastane kot odziv na zmanjšane zmožnosti zaradi posledic možganske poškodbe, nesprejemanje lastnega stanja po PMP, zmanjšano samostojnost ipd. Posameznik po PMP lahko doživlja konflikt med lastnimi potrebami in željami ter zahtevami okolja, sprožilec agresivnega vedenja pa lahko predstavlja tudi strah pred doživljanjem neuspeha. Ob soočanju z realnimi 
težavami, ovirami in neuspehi, ki so neposredna posledica poškodbe, namreč lahko pride tudi do povratnih negativnih učinkov na posameznikov sistem prepričanj, pričakovanj in stališč o samem sebi, prevlade zunanjega vira nadzora in negativnega atribucijskega stila (Jakopec, 2010).

V nasprotju s siceršnjim okrevanjem na kognitivnem področju pa se osebnostne spremembe pogosto kažejo kot trajna sprememba (Jakopec, 2010), kar vpliva na posameznikovo uspešnost vključevanja $\mathrm{v}$ širše socialno okolje. Posamezniki s PMP prav tako poročajo o pomembni stopnji sprememb na področju koncepta selfa, ki se kaže v zaznani spremembi identitete. Obstoječi self je zaznan kot negativen $\mathrm{v}$ primerjavi s selfom pred PMP, kar se nadalje pozitivno povezuje $\mathrm{s}$ pojavnostjo depresije in žalovanja (Carroll in Coetzer, 2011).

Stopnja čustvenih težav med posamezniki z možgansko poškodbo je močno povezana s stališči o pomanjkanju nadzora nad lastnim položajem (Jakopec, 2010). Posamezniki z možgansko poškodbo, ki veljajo za bolje rehabilitirane, svoje uspehe manj pripisujejo zunanjim faktorjem, kljub temu pa imajo šibkeje izražen notranji lokus kontrole kot posamezniki brez možganske poškodbe (Izaute idr., 2008), zato je pri intervencijah, usmerjenih $\mathrm{v}$ spremembe pri posameznikih s PMP, treba ugotoviti tudi, čemu posamezniki pri spoprijemanju s spremembami, ki jih prinese možganska poškodba, pripisujejo uspehe, oz. krepiti občutek nadzora nad lastnim položajem ter občutek lastne vrednosti.

Pri delu s posamezniki po PMP opažamo težave pri sprejemanju lastnega stanja, pogosto so prisotni jeza, žalost in zanikanje. Sprejemanje lastnih zmanjšanih zmožnosti oz. žalovanje za neuresničenimi življenjskimi cilji, zastavljenimi pred PMP, sta procesa, ki vplivata na kakovost življenja posameznika po PMP in sta odvisna od psihološke opremljenosti posameznika. Izkušnje kažejo, da posamezniki s PMP, ki v nekem obdobju dosežejo funkcionalno stopnjo sprejemanja zmanjšanih zmožnosti in čustveno stabilnost, lahko ponovno doživijo razočaranje, žalost in jezo na osnovi sprožilne situacije ali zaradi povečanja uvida v lastno stanje. Opažamo tudi, da imajo posamezniki s PMP, pri katerih so uvid in kognitivne funkcije težje oškodovani, višjo samopodobo in manjšo stopnjo čustvenih težav. Možna razlaga je, da obrambni mehanizmi vplivajo na zmanjšanje sposobnosti uvida, kar na posameznika vpliva ugodno zaradi zmanjšanja vpliva čustvenih težav (Cooper-Evans idr., 2008).

\section{Drugi dejavniki tveganja}

Komorbidnost je pri posameznikih z možgansko poškodbo pogosta, t. i. dvojne diagnoze predstavljajo dejavnik uspešnosti izvajanja intervencij za zmanjševanje pojavnosti agresivnih vedenj, predvsem $\mathrm{z}$ vidika urejenosti medikamentozne terapije ter kronificiranosti duševne motnje.

Nekateri negativni vedenjski vzorci imajo svoj izvor že v času pred možgansko poškodbo in so po njej še toliko bolj izraženi, na primer pojavljanje agresivnih vedenj pred možgansko poškodbo se povezuje s pojavljanjem verbalne agresivnosti po možganski poškodbi (James in Young, 2013). Včasih tudi težje določimo vzrok za posamezno spremembo $\mathrm{v}$ vedenju, tako da na prvi pogled deluje, da ima spontano genezo (Merc in Šemrov, 2013).
Na pojavnost pa lahko vplivajo tudi drugi situacijski dejavniki (npr. spremenjena družinska situacija, spremembe v socialni varnosti, poslabšanje zdravstvenega stanja, zloraba alkohola ipd.), ki povzročijo povečano razdražljivost, s čimer se možnost za pojavljanje agresivnih oblik vedenja poveča.

\section{Obravnava agresivnega vedenja v procesu dolgotrajne rehabilitacije}

Posamezniki s PMP se v vsakodnevnem življenju soočajo z različnimi izzivi. Zaradi posledic možganske poškodbe lahko razvijejo zelo različne, tudi neprimerne načine zadovoljevanja vsakdanjih potreb in doseganja ciljev. Zatečejo se lahko $\mathrm{k}$ agresivnemu in za okolico motečemu vedenju. Slabša sposobnost inhibicije odziva pa še dodatno vpliva na pojavnost neprimernega vedenja. Zaradi tega osebe s PMP ob stiku z zahtevami okolja pogosto doživljajo neuspehe oz. se ne uspejo uspešno reintegrirati v družbo (Vidergar in Šemrov, 2018).

Pri obravnavi agresivnih oblik vedenja naletimo na nekaj omejitev. Najbolj pomembna je ta, da se agresivno vedenje lahko kaže v več različnih oblikah, pri čemer univerzalna metoda za ocenjevanje in obravnavo ne obstaja (Wood in Thomas, 2013). Zaradi večjih razlik v etiologiji in obsegu možganske poškodbe so intervencije individualno prilagojene. Poleg ciljev rehabilitacije, ki se določijo v skladu z željami in potrebami posameznika s PMP in se jih zasleduje $\mathrm{v}$ procesu dolgotrajne rehabilitacije, se pri tistih $\mathrm{z}$ večjo pogostostjo pojavljanja agresivnega vedenja poveča tudi intenzivnost obravnave. Pogoj za doseganje sprememb predstavlja motivacija za doseganje teh sprememb. Ob izpolnitvi omenjenega pogoja so individualne obravnave bolj pogoste, tehnike dela pa izbrane glede na lastnosti posameznika s PMP, pri čemer se upoštevajo razvitost in ohranjenost kognitivnih funkcij, osebnostne značilnosti, stabilnost razpoloženja ipd. Večinoma gre za razbremenilne, podporne, (psiho)edukacijske in svetovalne pogovore, po potrebi je vključena tudi tehnika nagrajevanja po načelih instrumentalnega pogojevanja, ki je pri obvladovanju agresivnega vedenja pogosto uporabljena metoda (Wood in Alderman, 2011). Na takšen način se posamezniku s PMP nudi podporo, se mu pomaga pri učenju kompenzatornih načinov reagiranja, nudi povratno informacijo ter spremlja stanje.

Pri obravnavi agresivnega vedenja po PMP je treba upoštevati, da so napredki pri osebah s zmerno in težjo kronificirano možgansko poškodbo majhni in omejeni na konkretne situacije (Jakopec, 2010; McDonald idr., 2008; Merc in Šemrov, 2013; Wood in Alderman, 2011). Večinoma je pojavljanje agresivnega vedenja zaradi trdovratnosti vedenjskih vzorcev vezano na neposredne meritve, saj oškodovanost procesov miselne prožnosti po možganski poškodbi ne omogoča generalizacije naučenega zunaj konkretne situacije, prav tako je za razvoj veščin in vedenjskih sprememb potrebnih več ponovitev (Whiting idr., 2015). Tako se dogaja, da je treba enake načine kompenzatornih oblik vedenja ponavljati v več med seboj podobnih situacijah. Zaradi intenzivnosti čustev, ki spremljajo vedenjski odziv, je s posameznikom s PMP o povodih, vzrokih in kompenzatornih 
načinih reagiranja bolj smiselno izvajati pogovore po tem, ko se čustveno stanje stabilizira.

Doseganje sprememb v vedenju posameznika s PMP lahko poteka na treh ravneh. Prva predstavlja spremembo pri posamezniku s PMP (prepoznavanje sprožilnih situacij, učenje kompenzatornih načinov reagiranja ipd.), druga predstavlja spremenjen odziv okolja (če je možno, okolje prilagodimo v tej meri, da s svojimi karakteristikami izzove čim manj sprožilnih situacij), tretja raven pa predstavlja adaptacijo situacije. $\mathrm{Na}$ ravni zaposlenih so predvsem pomembni prepoznavanje frustracije, uporabnikove jeze in njenih drugih pojavnih oblik ter eksploracija vzrokov. Če prilagoditev samega pristopa osebja ne zadostuje, je treba na ustrezen način organizirati situacijo (predpriprava prostora, zmanjševanje motečih in sprožilnih dejavnikov, zmanjšanje intenzivnosti programa ipd.). Slednje poteka tako, da se skuša situacije prilagoditi na način, da v čim manjši možni meri izzivajo neželene odzive pri posamezniku s PMP, kar vključuje dobro poznavanje njegovih čustvenih, kognitivnih in vedenjskih značilnosti ter sprožilnih dejavnikov. Po drugi strani pa se $\mathrm{z}$ oblikovanjem ustreznega odziva zaposlenih, kadar je do agresivnega vedenja že prišlo, lahko doseže zmanjšanje vpliva agresivnega vedenja tako pri posamezniku s PMP kot tudi zmanjša stres pri zaposlenih. Sprememba odziva in sprememba situacije sta lahko tudi edini možni spremembi predvsem $\mathrm{v}$ primerih težjih možganskih poškodb in trdovratnejših negativnih vedenjskih vzorcih (Merc in Šemrov, 2013).

Kljub veliki strukturiranosti okolja je nerealno pričakovati, da do agresivnih oblik vedenja ne bo prihajalo, vendar lahko poznavanje problematike pripomore $\mathrm{k}$ zmanjševanju tako pojavnosti kot tudi vpliva. Pomembno je poudariti, da se bodo posamezniki s PMP brez ustrezne obravnave, ki bi prinašala trajnostne in celostne dosežke, s težavo trudili vzpostaviti produktivno in smiselno življenje (Kreutzer idr., 2018). Prizmanjševanju neprimernih odzivov priposamezniku s PMP je tako ključno poznavanje njegovih šibkejših, prav tako pa tudi močnejših področij funkcioniranja $v$ vsakodnevnih situacijah, kar ugotavljamo s (psiho)diagnostiko, $\mathrm{z}$ opazovanjem posameznika $\mathrm{v}$ medosebnih interakcijah, izmenjavo informacij v multidisciplinarnem timu, pomemben vir informacij pa predstavljajo tudi svojci.

\section{Zaključek}

PMP predstavlja nepredviden dogodek v življenju človeka, pri čemer se pri prilagajanju na spremenjene zmožnosti lahko pojavljajo različne oblike agresivnega vedenja kot posledica psihoorganske spremenjenosti oz. kot odziv na frustracijo in zahteve okolja. V dolgotrajni rehabilitaciji oseb s PMP je vedenjska problematika pogosta in zahteva multidisciplinarno obravnavo. Kljub temu da so napredki omejeni na konkretne situacije, pa strokovno delo s posameznikom po PMP podpira uspešnost vključevanja $\mathrm{v}$ širše okolje $\mathrm{z}$ učenjem in povratnimi informacijami glede primernosti vedenja v situaciji. Tovrstna obravnava preprečuje potencialno negativne posledice agresivnega vedenja za posameznika s PMP in zaposlene in ima $\mathrm{v}$ procesu dolgotrajne rehabilitacije kliničen in ekonomski smisel.

\section{Literatura}

Anson, K. in Ponsford, J. (2006). Coping and emotional adjustment following traumatic brain injury. Journal of Head Trauma Rehabilitation, 21(3), 248-259.

Arciniegas, D. B. in McAllister, T. W. (2008). Neurobehavioral management of traumatic brain injury in the critical care setting. Critical Care Clinics, 24(4), 737-765.

Belchev, Z., Levy, N., Berman, I., Levinzon, H., Hoofien, D. in Gilboa, A. (2017). Psychological traits predict impaired awareness of deficits independently of neuropsychological factors in chronic traumatic brain injury. British Journal of Clinical Psychology, 56(3), 213-234.

Carroll E. in Coetzer, R. (2011). Identity, grief and self-awareness after traumatic brain injury. Neuropsychological Rehabilitation: An International Journal, 21(3), 289-305.

Cattran, C., Oddy, M. in Wood, R. (2011). The development of a measure of emotional regulation following acquired brain injury. Journal of Clinical and Experimental Neuropsychology, 33(6), 672-679.

Cooper-Evans, S., Alderman, N., Knight, C. in Oddy, M. (2008). Self-esteem as a predictor of psychological distress after severe acquired brain injury: An exploratory study. Neuropsychological Rehabilitation, 18(5-6), 607-626.

Čižman Štaba, U. in Sagadin, M. (2016). Nezgodna možganska poškodba [Traumatic brain injury]. V D. S. Kovačič (ur.), Psihologija v rehabilitaciji oseb s telesno in povezano duševno zmanjšano zmožnostjo (str. 127-137) [Psychology in rehabilitation of individuals with physical and related mental impairment (pp. 127-137)]. Ljubljana: Univerzitetni rehabilitacijski inštitut Republike Slovenije - Soča.

Dimoska-Di Marco, A., McDonald, S., Kelly, M., Tate, R. in Johnstone, S. (2011). A meta-analysis of response inhibition and Stroop interference control deficits in adults with traumatic brain injury (TBI). Journal of Clinical and Experimental Neuropsychology, 33(4), 471-485.

Grabljevec, K. (2009). Nezgodne možganske poškodbe v prihodnosti: Zaščita ali reparacija [Traumatic brain injuries in the future: Protection or reparation]. Rehabilitacija, 8(supl. 1), 14-17.

Grabljevec, K. (2011).Z dokazi podprta rehabilitacija bolnikov po možganski poškodbi [Evidence based rehabilitation of patients after traumatic brain injury]. Rehabilitacija, 10(1), 111-115.

Hart, T., Sherer, M., Whyte, J., Polansky, M. in Novack, T. A. (2004). Awareness of behavioral, cognitive, and physical deficits in acute traumatic brain injury. Archives of Physical Medicine and Rehabilitation, 85(9), 1450-1456.

Izaute, M., Durozard, C., Aldigier, E., Teissedre, F., Perreve, A. in Gerbaud, L. (2008). Perceived social support and locus of control after a traumatic brain injury. Brain Injury, 22(10), 758-764.

Jakopec,Z.(2010). Psihološki dejavnikiv poklicnirehabilitaciji oseb po nezgodni možganski poškodbi [Psychological factors in vocational rehabilitation following traumatic brain injury]. Rehabilitacija, 9(1), 58-65. 
James, A. I. W. in Young, A. W. (2013). Clinical correlates of verbal aggression, physical aggression and inappropriate sexual behaviour after brain injury. Brain Injury, 27(10), $1162-1172$.

Kelly, G., Brown, S., Todd, J. in Kremer, P. (2008). Challenging behaviour profiles of people with acquired brain injury living in community settings. Brain Injury, 22(6), 457-470.

Kreutzer, J. S., Marwitz, J. H., Sima, A. P., Mills, A., Hsu, N. H. in Lukow, H. R. II (2018). Efficacy of the resilience and ajustment intervention after traumatic brain injury: A randomized controlled trial. Brain Injury, 32(8), 963-971.

McDonald, S., Hunt, C., Henry, J. D., Dimoska, A. in Bornhofen, C. (2010). Angry responses to emotional events: The role of impaired control and drive in people with severe traumatic brain injury. Journal of Clinical and Experimental Neuropsychology, 32(8), 855-864.

McDonald, S., Tate, R, Togher, L., Bornhofen, C., Long, E., Gertler, P. in Bowen, R. (2008). Social skills treatment for people with severe, chronic acquired brain injuries: A multicenter trial. Archives of Physical Medicine and Rehabilitation, 89, 1648-1659.

Merc, R. in Šemrov, M. (2013). Pristop k vedenjskim težavam pri delu z osebami z možgansko poškodbo [Approach to behavioural problems in brain injury]. Defektologica slovenica: Revija defektologov in specialnih pedagogov Slovenije, 21(1), 7-23.

Miller, L. A., Collins, R. L. in Kent, T. A. (2008). Language and the modulation of impulsive aggression. The Journal of Neuropsychiatry and Clinical Neurosciences, 20(3), 261-273.

Pearce, B., Cartwright, J., Cocks, N. in Whitworth, A. (2016). Inhibitory control and traumatic brain injury: The association between executive control processes and social communication deficits. Brain Injury, 30(13-14), 1708-1717.

Radonjič Miholič, V. (2005). Zakaj lahko poškodba glave ovira kakovost življenja? [Why brain injury can impede quality of life?] V V. Košorok in K. Grabljevec (ur.), XVI. dnevi rehabilitacijske medicine: Poškodba glave - vpliv celovite nevrorehabilitacijske obravnave na funkcijski izid (str. 197-207) [XVI. Days of rehabilitation medicine: Head injury - the impact of comprehensive neurorehabilitation treatment on functional outcome (pp. 197-207)]. Ljubljana: Inštitut Republike Slovenije za rehabilitacijo.

Rees, L., Marshall, S., Hartridge, C., Mackie, D. in Weiser, M. (2007). Cognitive interventions post acquired brain injury. Brain Injury, 21(2), 161-200.

Ridderinkhof, K. R., van den Wildenberg, W.P.M., Segalowitz, S. J. in Carter, C. S. (2004). Neurocognitive mechanisms of cognitive control: The role of prefrontal cortex in action selection, response inhibition, performance monitoring, and reward-based learning. Brain and Cognition, 56(2), 129-140.
Starovasnik Žagavec, B. (2012). Nevropsihološka diagnostika sposobnosti prepoznavanja in celostnega združevanja informacij - možnosti za ocenjevanje, trening in kognitivno nevrorehabilitacijo [Neuropsychological assessment of recognition ability and complex integration of information - possibilities for assessment, training and cognitive rehabilitation]. Rehabilitacija, 11(supl. 1), 24-29.

Tateno, A., Jorge, R. E. in Robinson, R. G. (2003). Clinical correlates of aggressive behaviour after traumatic brain injury. The Journal of Neuropsychiatry and Clinical Neurosciences, 15(2), 155-160.

Todd, J., Loewy, J., Kelly, G., in Simpson, G. (2004). Managing challenging behaviours: Getting interventions to work in nonspecialised community settings. Brain Impairment, 5(1), 42-52.

Vaishnavi, S., Rao, V. in Fann, J. R. (2009). Neuropsychiatric problems after traumatic brain injury: Unraveling the silent epidemic. Psychosomatics, 50(3), 198-205.

Vidergar, S. in Šemrov, M. (2018). Integracija in inkluzija $\mathrm{v}$ procesu rehabilitacije oseb po pridobljeni možganski poškodbi [Integration and inclusion in the rehabilitation of persons with acquired brain injury]. Iskanja, 36(57), $75-81$.

Whiting, D. L., Deane, F. P., Simpson, G. K., McLeod, H. J. in Ciarrochi, J. (2015). Cognitive and psychological flexibility after a traumatic brain injury and the implications for treatment in acceptance-based therapies: A conceptual review. Neuropsychological Rehabilitation, 27(2), 263-299.

Wood, R. L. in Alderman, N. (2011). Applications of operant learning theory to the management of challenging behavior after traumatic brain injury. Journal of Head Trauma Rehabilitation, 26(3), 202-211.

Wood, R. L. in Thomas, R. H. (2013). Impulsive and episodic disorders of aggressive behaviour following traumatic brain injury. Brain Injury, 27(3), 253-261. 